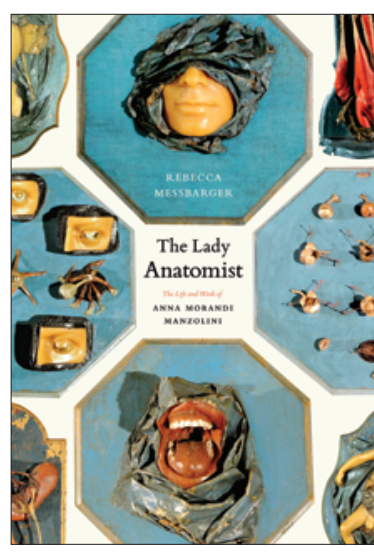

\section{The lady anatomist}

\author{
The life and work of Anna Morandi Manzolini
}

Rebecca Messbarger

The University of Chicago Press. Chicago, Illinois, USA. 2010.

248 pp. \$35.00. ISBN: 978-0-226-52081-0 (hardcover).

\section{Reviewed by Sabine Hildebrandt}

Division of Anatomical Sciences, Department of Medical Education, University of Michigan Medical School, Ann Arbor, Michigan, USA.

E-mail: shilde@umich.edu ebecca Messbarger presents in The Lady Anatomist the biography of Anna Morandi Manzolini, a wax modeler and anatomist in eighteenth-century Bologna, Italy. This astonishing and greatly informative account leaves the reader wondering why this place and time in history, and the stories of the men and women involved, have not been more prominent in discussions of the period of enlightenment and the history of anatomy.

Anna Morandi (1714-1774) married the Bolognese artist and anatomist Giovanni Manzolini and became not just his spouse and mother of their children, but also his colleague. The couple worked on the production of anatomical wax models, first in collaboration with the artist Ercole Lelli on a papal commission for the University of Bologna's Anatomy Museum. After a disagreement between Lelli and Manzolini, Morandi and her husband pursued anatomical dissections and wax model production in their home laboratory. Over time they had legal access to more than a thousand unclaimed bodies delivered from the public hospitals of Bologna. Their work was famous for the beauty and trueness of the wax models as well as the accuracy of their anatomical observations. Local and international visitors to the laboratory were surprised by Morandi's hands-on involvement in anatomy and her scientific erudition, as Morandi, rather than Manzolini, presented their common work to the public. The couple defined a new purpose for the anatomical wax model: rather than using the medium as illustration for more accurate art of the nude, they employed it as a teaching tool for accurate anatomy. After Manzolini's death in 1755, Morandi continued her scientific work, and her reputation and commissions reached from Italy to London and the Russian court.
The author makes a convincing argument for Morandi's being not just an inspired craftswoman, as she had been portrayed by previous biographers, but also a wellread and innovative scientist, anatomical teacher, and scholar who followed her own scientific agenda. This point is proven by Messbarger's intensive analysis of Morandi's anatomical notebooks and letters, the testament of the wax models themselves, and the writings of numerous contemporary witnesses, both laymen and scholars. Morandi engaged in scientific disputes, always citing her own observations in the dissection of human bodies. Her areas of special expertise included the developmental anatomy of the skeleton, the reproductive systems of men and women, as well as the sensory organs. Her analytical and realistic view of male and female bodies was at odds with contemporary assertions concerning the "inferior female." Despite Morandi's position as public lecturer at the University of Bologna, her colleagues viewed her more as an artist then a scientist. This fact together with the popularity of the Florentine collection of wax models at La Specola museum, opened shortly after Morandi's death, may have led to her relative obscurity in history.

Messbarger's research proves to be a treasure trove of surprising news for the student of the history of anatomy. She reveals the interest of Pope Benedict XIV in anatomy, which led to a recommendation for voluntary body donation; the high status of women scientists in eighteenth-century Bologna; and Morandi and Manzolini's innovative teaching of anatomy with wax models, which was similar to modern anatomical teaching with plastinated human specimens. Messbarger's book is much more than the biography of a rare female scientist. The author paints a rich canvas of the political, cultural, and scientific life of eighteenth-century Italy and Bologna specifically. She explores the network of thoughts and personalities that made the existence of a female scientist during this era possible. By approaching her subject from this wider cultural background and with her deep understanding of the Italian world of the time, Messbarger, a linguist and cultural historian, accesses a diverse array of archival and literary sources, including contemporary autobiographies and letters, that give new insights into the specific developments in anatomy of that time period. Incidentally, the author made an effort to learn as much as possible about the science and modern teaching of anatomy to make her approach, which like Morandi's spans the arts and the sciences, a most fruitful one.

The book is a fascinating and enlightening read, if not always an easy one; its language is at times quite dense. However, this may be a necessity in Messbarger's discipline, an integrated approach to history - one that is a perfect model for the successful exploration of the history of the sciences. The circle of potentially enthralled readers should be wide, spanning from students of gender history to those of anatomical history and the history of enlightenment.

A word should be said about the "physicality" of the book itself. In the time of digital books, it is a joyful surprise to hold and read such a beautiful new book as The Lady Anatomist. It is pleasing to eyes and hands (important senses to Morandi and Messbarger): the format is wide, the layout generous, the paper heavy, the reproductions and colors of the many important images luscious. May this work have many readers! 